\section{Canonical correlation analysis: A BASIC system for microcomputers}

\author{
DANIEL COULOMBE \\ University of Ottawa, Ottawa, Ontario, Canada
}

Canonical correlation analysis is a multivariate dataanalysis technique aimed at the examination of the correlation between two linear combinations of variables. The foundations as well as the mechanics involved are adequately described in most textbooks on multivariate analysis (Lindeman, Merenda, \& Gold, 1980; Marascuilo \& Levin, 1983; Pedhazur, 1982; Tabachnick \& Fidell, 1983). Although the use of canonical correlation is infrequent in the behavioral sciences literature, the development of computer programs aimed at the solution of canonical correlation problems has substantial practical and methodological implications. Indeed, canonical correlation is a very general technique, in the sense that many other statistical analytic methods could be demonstrated to be special cases of canonical correlation. Depending on the number of variables in each set, and on the nature of those variables (continuous or discrete), canonical correlation can reduce to simple linear correlation, multiple regression, discriminant analysis, analysis of variance, analysis of covariance, multivariate ANOVA, and chisquare test of independence (Marascuilo \& Levin, 1983). Thus, a single program for solving canonical correlation problems could be useful for the solution of a wide variety of statistical problems.

The purpose of the program system presented here is to perform canonical correlation analysis, including the generation of the structure matrices, tests of significance, analysis of redundancies and the computation of canonical scores. This system can be linked to a multiple regression package described earlier (Coulombe, 1983) to obtain a scattergram illustrating the relationship between the canonical variates, or to perform further analysis on those scores. All critical computations are performed in double precision to minimize rounding errors. The routine to obtain the eigenstructure of the canonical matrix was derived from Veldman's (1967) algorithm.

Input. At the start of the program, the user is provided with a menu from which the data-input mode can be selected. Data (raw scores or correlation matrix) can be entered either from the keyboard or from a disk file. In either case, the program requests the number of subjects, the number of variables in the X-set (containing the greater number of variables), and the number of variables in the $Y$-set (containing the smaller number of variables). If raw scores are to be entered from the keyboard, the program

The author's mailing address is: School of Psychology, University of Ottawa, 275 Nicholas, Ottawa, Ontario, Canada K1N 6N5. prompts sequentially for each score obtained by a subject on each variable. If raw data are to be input from disk files, the program prompts for the name of each file to be read. If necessary, the data files can be created and edited with a data file editor described previously (Coulombe, 1983). If a correlation matrix is to be input from the keyboard, the program prompts for each upper triangular element of R. Alternatively, if a correlation matrix is to be entered from a disk file, the program requests the name of the file containing the correlation matrix. Such a matrix can be created with a provided utility (CORMAT.BAS), from raw scores stored in disk files.

Output. All outputs are directed to the screen display. To obtain line-printer output, the PRINT statements should be changed to LPRINT statements or to any routing instructions available on the system in use. It includes a listing of: (1) the means and standard deviations observed for each variable; (2) the correlation matrix between all pairs of variables; (3) the canonical matrix $\left(R_{x x}{ }^{-1} R_{y x} R_{y y}{ }^{-1} R_{x y}\right)$; (4) the canonical correlations and associated tests of significance $\left(R_{\text {can }}, R_{\text {can }}^{2}\right.$, lambda, chisquare, degrees of freedom, and percentage of trace); (5) the canonical weights for $X$ and $Y$; (6) the structure coefficients, including all possible correlations between any original $\mathrm{X}$ or $\mathrm{Y}$ variable and any canonical $\mathrm{X}$ or $\mathrm{Y}$ variate; (9) the percentages of total variance extracted by each factor for both $\mathrm{X}$ and $\mathrm{Y}$; and (8) the coefficients of redundancy. Finally, if raw data are input, the user is provided with the possibility of computing canonical scores for any set of canonical variates. If computed, those scores are saved on disk files for ulterior use, in a format compatible with the MULREG system (Coulombe, 1983).

Program Language and Requirements. The two programs contained in the present system (CANCOR.BAS and CORMAT.BAS) were written in GW-BASIC on a 384K Tandy 2000 with two disk drives, under MS-DOS. This language is directly compatible with that of the IBM PC and work alikes. Both programs can be easily transported to other computers that use Microsoft BASIC. The CANCOR program occupies about $9.0 \mathrm{~K}$ of memory, leaving approximately $52 \mathrm{~K}$ for execution. Correlation matrices including 60 variables can be input and analyzed on the Tandy 2000 and IBM PC. If raw data are input, problems involving 500 subjects and a total of 20 variables can be analyzed.

The computation time required for an analysis depends on the computer clock speed and on the total number of variables and subjects. A problem involving 200 subjects and a total of 20 variables (10 variables in each set) was solved within $11.3 \mathrm{~min}$ on the Tandy 2000 (8-MHz clock speed).

Availability. A listing of the programs is available free of charge from the author, School of Psychology, University of Ottawa, 275 Nicholas, Ottawa, Ontario, Canada K1N 6N5. 


\section{REFERENCES}

Coulombe, D. (1983). MULREG: A multiple regression analysis system for microcomputers. Behavior Research Methods \& Instrumentation, 15, 608.

Lindeman, R. H., Merenda, P. F., \& Gold, R. Z. (1980). Introduction to bivariate and multivariate analysis. Glenview, Il: Scott, Foresman \& Company.

Marascuilo, L. A., Levin, J. R. (1983). Multivariate statistics in the social sciences: A researcher's guide. Monterey, CA: Brooks/Cole.
Pedhazur, E., J. (1982). Multiple regression in behavioral research. New York: Holt, Rinehart \& Winston.

TABACHNICK, B. G., FidELL, L. S. (1983). Using multivariate statistics. New York: Harper \& Row.

VELDMAN, D. J. (1967). FORTRAN programming for the behavioral sciences. New York: Holt, Rinehart \& Winston.

(Revision accepted for publication September 19, 1984.) 